\title{
RESTRICGIONES EN EL ACCESO AL MERCADO DE VALORES DEL PERÚ
}

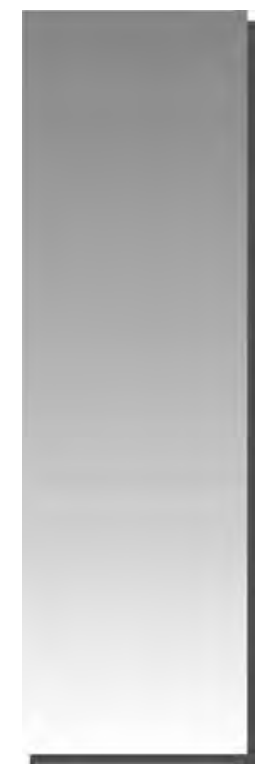

Pablo W. Mauricio Pachas* pwmauricio@yahoo.es

\section{RESUMEN}

El presente artículo es extraído de la tesis Deficiencias estructurales de la oferta de activos financieros en el mercado de valores del Perú" cuyo autor es el suscrito, y que trata las principales causas de la falta de instrumentos financieros que origina exceso de liquidez en el mercado de valores, causando emigración de capitales, como los de las AFP, que serían invertidos en el extranjero.

En el estudio se plantea el problema a través de la interrogante ¿A qué se debe el déficit de activos financieros en el mercado de valores del Perú?, lo que conlleva a establecer como hipótesis de estudio: "La deficiente regulación y promoción del Mercado de Valores del Perú contrae el acceso de las empresas a este mercado" contrastado con los resulatdos de la encuesta aplicada.

En su desarrollo se destaca la poca participación de empresas que ofertan instrumentos financieros en el mercado de valores, descritos por alrededor de 220 empresas al año 2010 y si se consideran los fondos de inversión ascenderían a 263 empresas. No obstante que en el análisis se ha determinado que existe un universo de 913 grandes empresas en el país con condiciones económicas y financieras que exige la demanda del mercado, sin embargo, únicamente 144 grandes empresas participan, equivalente al 16\% del total, determinándose que 769 grandes empresas están ausentes del mercado de valores.

De otro lado, se establece que la legislación vigente del mercado de valores encarece el costo de emisiones de bonos y acciones, debido a los elevados trámites en el proceso de estructuración, gastos legales, registrales, clasificadoras, etc., que origina elevado costo de las emisiones, más del 3\% del costo requerido para un monto de emisión de 5 millones de dólares para bonos. Tales restricciones en el acceso al mercado se sustentan en las consultas y respuestas aplicadas a las grandes empresas que no participan, quienes han manifestado en un nivel del $37 \%$, que estarían motivadas a ingresar al mercado de valores con la flexibilización de requisitos de las emisiones y reducción de costos.

\footnotetext{
* Economista, Magíster en Economía, Doctor en Ciencias Contables y Empresariales UNMSM. Ex-Director General de Planificación, Administración y Asesor en el Sector Público, Gerente de Financieras y Sociedad Agente de Bolsa. Profesor Visitante, Becado por el Departamento de Estado de EE UU a las Universidades de New York, Pace, Columbia, Yale en New Haven-Connecticut, Northeastern, Suffolk, Boston, Massachusetts-EE UU. Consultor (Corporación global Monitor). Ex Director de Postgrado y Profesor Principal de la Facultad de Ciencias Administrativas-UNMSM.
} 
Asimismo se establece la necesidad de adoptar acciones y medidas económicas no de carácter legal sino de mercados, para impulsar el acceso al mercado de más empresas, a fin de aumentar la oferta de instrumentos financieros de negociación (títulos-valores) de manera significativa, fortaleciendo el enfoque de mercado competitivo por parte de la Regulación, hoy Superintendencia del Mercado de Valores.

Palabras clave: escasos valores

\begin{abstract}
The present article is extracted from the Thesis "structural Deficiencies of the offer of financial assets on the stock market of Peru" authored by the undersigned and it shows the principal reasons of the lack of financial instruments that originates excess of liquidity on the stock market, causing capital emigration, such as AFP that have to be invested abroad.

The study raises the question Why is there a deficit of financial assets in the stock market in Peru? leading to our hypotheses: " The deficient regulation and promotion of the Stock market of Peru contracts the access of the companies to this market " confirmed with the results of the applied survey.

In its development highlights is outlined small participation of companies offering financial instruments in the stock market, described by some 220 companies by 2010 and if we consider mutual funds amount, to 263 companies. Although the analysis has determined that there is a universe of 913 large companies with economic and financial conditions required by that market demand, Only 144 big companies are involved, that is $16 \%$ of the total, determining that 769 big companies are absent of the stock market.

On the other hand, it is found that the governing law increases the price of the cost of emission of bonds and actions, due to the high steps in the process of structure, legal expenses, registration, sorting, etc. which causes high cost of emissions, being more than 3\% of cost required for emission of 5 million dollars for bonds. Such restrictions on market access are based in the queries and answers applied to the big companies that do not take part, those who have demonstrated in a level of 37 $\%$, would be encouraged to enter the market with more flexible and emissions requirements and cost reduction.

Likewise there is established the need to adopt actions and economic measures not of legal character but of markets, to stimulate the access to the market of more companies, in order to increase the supply of trading financial instruments of negotiation (titles-values) significantly, strengthening the approach of competitive market by Regulation of today Superintendence of the Stock market.
\end{abstract}

Keywords: low values

\section{INTRODUCCIÓN}

El estudio trata el problema del déficit de activos financieros en el mercado de valores y la deficiente regulación y promoción. Brecha entre la demanda y oferta de valores, que ha venido originando un exceso significativo de liquidez en el mercado ante la escasa participación de empresas en el Mercado de Valores Peruano, conllevando a que capitales acumulados en el país, como los de las AFP, tengan que invertirse en el extranjero, en desmedro de la inversión interna y de la generación de empleo en el país, situación que revela la existencia de fuertes restricciones en el acceso de las empresas a este mercado.

En este sentido se propone como objetivo, describir las deficiencias en el mercado de valores del Perú relacionadas a la limitada participación de empresas que ofertan instrumentos financieros y se plantea como hipótesis de estudio que "La deficiente regulación y promoción del Mercado de Valores del Perú contrae el acceso de las empresas a este mercado".

Asimismo se destaca la limitada participación de empresas que ofertan instrumentos financieros en el mercado de valores, que al 2010 alcanzaban alrededor de 220 empresas y si se consideran los fondos de inversión ascenderían a 263 empresas. No obstante que en el análisis se ha determinado que existe un universo de 913 grandes empresas en el país con condiciones económicas y financieras exigidas por el mercado, sin embargo de estas, únicamente participan 144 grandes empresas equivalente al $16 \%$ del total, determinándose un potencial de 769 grandes empresas que no participan en el Mercado de Valores del país. 


\section{Acerca de la problemática}

La demanda en nuestro mercado de valores, se ha caracterizado por un ritmo de crecimiento, dado el favorable entorno macroeconómico. Tal incremento de la demanda de valores se debe a la participación activa de los Inversionistas Institucionales, que se han orientado a compras de bonos, como las que realizan las compañías de seguros, fondos de pensiones y fondos mutuos. El apreciable exceso de demanda debido a la poca oferta de instrumentos financieros, se viene describiendo desde el 2000, brecha que se mantiene en la actualidad, como referencia a setiembre del 2010 la demanda alcanzo a \$53,266.6 millones de dólares mientras que la oferta fue de \$15, 294,3 millones de dólares.

La falta de instrumentos financieros y la creciente demanda, establece una importante brecha entre la oferta y demanda, lo que constituye el principal problema que hay que resolver, situación que será investigada, planteándose la siguiente interrogante: ¿Por qué el déficit de la oferta de activos financieros en el mercado de valores del Perú están relacionadas a la limitada participación de empresas que ofertan instrumentos financieros? y que ante el exceso de demanda de títulos - valores conlleva que capitales acumulados en el país tengan que invertirse en el extranjero, como el caso de las AFP.

Dada la situación de exceso de oferta de fondos en el mercado por falta de instrumentos financieros (valores) de negociación y de otro lado la necesidad de inversiones en el sector real en nuestro país, no se conocen acciones y ni estrategias por revertir esta tendencia por parte del gobierno - SMV, lo que justifica la realización del presente trabajo de investigación como aporte, cuya finalidad es investigar a las principales empresas a través de las siguientes interrogantes: ¿Por qué no participan en el mercado de valores? ¿Tienen conocimientos de las ventajas, beneficios del mercado de valores? Asimismo trata de explorar mecanismos, instrumentos y medidas que incremente la participación de empresas en el mercado de valores e incremente la oferta de instrumentos de negociación como vehículo de inversión interna, cada vez de mayor necesidad para que en el país se incremente el empleo y se reduzca la pobreza.

Pese al problema descrito, el mercado en los últimos años ha venido creciendo su volumen de negociación, como se aprecia en el financiamiento a través de la Oferta Pública Primaria del sector privado emitiendo acciones, bonos-obligaciones. Estos mayores montos inscritos fueron a su vez acompañados por un incremento del número de agentes económicos que optaron por acceder al mercado de valores para el financiamiento de sus actividades productivas, sobre todo a través de la emisión de bonos corporativos, en el caso de empresas no financieras y de bonos de arrendamiento financiero y subordinados, para el caso de instituciones financieras. Así, de \$2, 059,8 millones de emisiones inscritas en el 2004 ascendieron a \$ 7,046.5 millones de emisiones inscritas en el 2009 , destacando las emisiones de bonos corporativos que de \$1, 340,3 millones en el 2004 ascendieron a \$ 5,694 millones en el 2009 seguidos por emisiones de Bonos de arrendamiento financiero. Evolución de incremento de emisiones, se puede observar en el Cuadro № 1 .

Cuadro N. ${ }^{\circ}$ 1. Inscripciones de Oferta Pública por tipo de valor en el Mercado Primario.

\begin{tabular}{|c|c|c|c|c|c|c|}
\hline MODAUDAD DE EMISIÓN & 2004 & 2005 & 2006 & 2007 & 2008 & 2009 \\
\hline \multicolumn{7}{|l|}{ L. OFERTA PÚBLICA2f: } \\
\hline EMISIONES INSCRT AS POR INSTRUMENTO & $2,059,869$ & $2,085,880$ & $3,083,553$ & $3,943,557$ & $4,864,440$ & $7,046,496$ \\
\hline A ACCIONES & 2.154 & 1.864 & & 296,915 & $=$ & \\
\hline B. BONOS & $1,622,551$ & $1,546,943$ & $2,559,087$ & $3,158,987$ & $4,387,447$ & $6,226,125$ \\
\hline -B. DE ARRENDAMIENTO FINANCIERO & 21,000 & 254,000 & 211,000 & 331,038 & 799,505 & 110,400 \\
\hline -B. CORPORATIVOS & $1,340,376$ & $1,005.787$ & $2,134,916$ & $2,334,362$ & $3,138,965$ & $5,694,005$ \\
\hline -B. HIPOTECARIOS & 30,000 & 10,000 & 70,000 & - & 110,000 & 0 \\
\hline -B SUBORDINADOS & - & 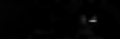 & - & 190,774 & 268,514 & 389,478 \\
\hline -B. DE TITULIZACIÓN & 231,175 & 277.156 & 143,151 & 136,202 & 70.462 & 32,243 \\
\hline C. INSTRUMENTOS DE CORTO PLAZO & 95,158 & 297735 & 316,811 & 509,851 & 322,484 & 614,929 \\
\hline -INSTRUM. DE CORTO PLAZO & 95,158 & 297,735 & 316,811 & 509,851 & 222,484 & 614,929 \\
\hline -INSTRUM. DE CORTO PLAZO DE TITULIZACIÓN & - & $=$ & $\therefore$ & $=$ & 100,000 & \\
\hline D CERTIFICADOS DE DEPÓSITO NEGOCIABLES & 340,005 & 239,337 & 207.675 & 144.415 & 154,509 & 205,443 \\
\hline
\end{tabular}

Fuente: Ex-CONASEV 
No obstante el incremento de valores inscritos en el mercado primario, es importante determinar las causas del déficit de instrumentos de deuda y capital emitido por empresas nacionales y encontrar las respuestas a ¿Por qué participan un número reducido de empresas? ¿Por qué grandes empresas, que son de elevada cantidad, no participan?

En este sentido resulta importante destacar el funcionamiento de los mercados financieros y de valores y sus ventajas, puesto que poseen una serie de mecanismos que permiten y facilitan la canalización de fondos provenientes de inversionistas o ahorradores hacia empresas o entidades que requieren financiamiento y apoyar el desarrollo de la actividad productiva o inversión al sector real del país. Si bien, el nivel de financiamiento en nuestro país a través del mercado de valores, comparado con el sistema financiero, aún es bajo, no deja de destacar sus ventajas y beneficios.

La importancia relativa del financiamiento a través del mercado de valores (emisiones primaria) en relación al sistema financiero nacional, aún sus niveles son muy bajos. Así las emisiones del sector privado con relación a la Liquidez del Sistema Financiero fue de $6.55 \%$ en 2002 , pasando a $10.77 \%$ en 2009 , mientras que las emisiones del sector público en 2002 fue de $13.40 \%$ pasando a $0.72 \%$ en 2009 , tendencia que requiere de medidas económicas y de mercado para ser revertida y profundizar el mercado de valores en el Perú. Tal evolución se puede apreciar en el Cuadro N. ${ }^{\circ} 2$.

\section{Métodos}

Los métodos comprenden el planteamiento del problema, los objetivos, así como la aplicación de técnicas, recopilación de información para contrastar las hipótesis de estudio, y luego determinar los resultados y discutirlos. El diseño de la investigación es por objetivos, hipótesis y variables.

En esta orientación, para determinar la población, se ha tomado en cuenta a los agentes económicos de mayor importancia económica en el país, como principal segmento de estudio, ubicados en Lima, aunque muchas de ellas también están en provincias o regiones. Es decir, como primera referencia poblacional, consideramos a las grandes empresas que se desarrollan en diferentes sectores productivos y que no participan del mercado de valores, a fin de contrastar nuestra hipótesis de estudio. Información que serán obtenidas de

Cuadro N. ${ }^{\circ}$ 2. Importancia relativa de las inscripciones en el mercado primario de valores: 2004 2009 (En soles)

\begin{tabular}{|c|c|c|c|c|c|c|c|c|}
\hline \multirow[t]{2}{*}{ AÑOS } & \multirow{2}{*}{$\begin{array}{l}\text { EMISIONES } \\
\text { DEL SECTOR } \\
\text { PRIVADO } 1 / . \\
\text { (A) }\end{array}$} & \multirow{2}{*}{$\begin{array}{l}\text { EMISIONES } \\
\text { DEL SECTOR } \\
\text { PÚBLICO } 21 . \\
\text { (B) }\end{array}$} & \multirow{2}{*}{$\begin{array}{l}\text { LIQUIDEZ } \\
\text { DEL SISTEMA } \\
\text { FINANCIERO } 3 / . \\
\text { (C) }\end{array}$} & \multirow{2}{*}{$\begin{array}{l}\text { PRODUCTO } \\
\text { INTERNO } \\
\text { BRUTO }^{3 / .} \\
\text { (D) }\end{array}$} & \multicolumn{4}{|c|}{ RELACIÓN PORCENTUAL } \\
\hline & & & & & $(A) /(C)$ & $(A) /(D)$ & $(\mathrm{B}) /(\mathrm{C})$ & $(\mathrm{B}) /(\mathrm{D})$ \\
\hline 2002 & 4,293 & 8,787 & 65,562 & 199,650 & $6.55 \%$ & $2.15 \%$ & $13.40 \%$ & $4.40 \%$ \\
\hline 2003 & 6,115 & 7,869 & 73,642 & 213,425 & $8.30 \%$ & $2.86 \%$ & $10.68 \%$ & $3.69 \%$ \\
\hline 2004 & 7,028 & 8,462 & 82,831 & 237,902 & $8.49 \%$ & $2.95 \%$ & $10.22 \%$ & $3.56 \%$ \\
\hline 2005 & 6,910 & 10,963 & 101,724 & $261,653^{*}$ & $6.79 \%$ & $2.64 \%$ & $10.78 \%$ & $4.19 \%$ \\
\hline 2006 & 10,067 & 6,314 & 123,329 & $302,255^{*}$ & $8.16 \%$ & $3.33 \%$ & $5.12 \%$ & $2.09 \%$ \\
\hline 2007 & 12,231 & 11,569 & 157,995 & $335,730^{*}$ & $7.74 \%$ & $3.64 \%$ & $7.32 \%$ & $3.45 \%$ \\
\hline 2008 & 14,219 & 2,880 & 163,946 & $372,793^{*}$ & $8.67 \%$ & $3.81 \%$ & $1.76 \%$ & $0.77 \%$ \\
\hline 2009 & 21,117 & 1,405 & 196,015 & 381,671 & $10.77 \%$ & $5.53 \%$ & $0.72 \%$ & $0.37 \%$ \\
\hline
\end{tabular}

1/. Considera los montos máximos inscritos en el Registro Público del Mercado de Valores por emisión. En el caso de las emisiones se considera, el monto de la emisión en el año en que se presentó el prospecto complementario.

21. Autorización de emisiones mediante Decretos Supremos y Decretos de Urgencia.

3/. Datos publicados por el BCRP. Cuadro 95 de la Nota Semanal del BCRP.

Fuentes: CONASEV, BCRP, MEF 
la CONASEV, BCRP, INEI, MEF, Cámara de Comercio de Lima, Ministerios de Trabajo, Producción y de otros centros de información especializados.

Para determinar la población de las grandes empresas, consideramos como referencia dos importantes fuentes: INEI y la otra privada, PERU: THE TOP 10000 Companies 2010, edición número 24, empresa: Perú top publications.
Según la fuente del INEI del 2006, las grandes empresas en el Perú ascendían a 800 equivalente al $0.02 \%$ del total de las empresa y aportan el $30 \%$ al PBI, mientras que las mypes representan el $99.63 \%$ del total de empresas en el país y contribuyen con el 34\% del PBI y emplean al 62\% de la PEA. Desagregado que se puede observar en el Cuadro N. ${ }^{\circ} 3$.

Cuadro N. ${ }^{\circ}$ 03: Principales empresas en el Perú - 2006

\begin{tabular}{|l|r|r|r|r|c|}
\hline Categoria & $\begin{array}{c}\text { Número } \\
\text { empresas }\end{array}$ & \multicolumn{1}{c|}{$\%$} & Empleo (PEA) & $\%$ & PBI (en \%) \\
\hline Sector privado & $3,229,197$ & 100,00 & $10,128,859$ & 70.4 & 82 \\
\hline Gran empresa & 800 & 0.02 & 544,924 & 3.8 & 30 \\
\hline Mediana empresa & 10,918 & 0.34 & 646,954 & 4.5 & 18 \\
\hline Pequeña empresa & 49,728 & 1.54 & $1,065,057$ & 7.4 & 9 \\
\hline Microempresa & $3,167,751$ & 98.10 & $7,871,924$ & 54.7 & 25 \\
\hline Sector público & & & $1,058,202$ & 7.4 & 9 \\
\hline Independientes & & & $2,642,633$ & 18.4 & 7 \\
\hline Trabaj. Del hogar & & & 550,615 & 3.8 & 2 \\
\hline Total & $3,229,197$ & & $14,380,309$ & 100.0 & 100 \\
\hline
\end{tabular}

Fuente: Encuesta Nacional de Hogares (ENAHO)- INEI para el año 2006. MTPE- Ministerio de Trabajo y Promoción del Empleo (2007).

De otro lado, la publicación de 2010 denominada, Peru: The Top 10000 Companies 2010, Edición Número 24, Empresa: Peru Top Publications; determina que las grandes empresas en el país en 2009 ascendieron a 913 en vez de 800 estimada por el INEI, por lo que consideremos a esta fuente como base para la presente investigación. Es decir, el universo a considerar como base es 913 grandes empresas.

Asimismo, esta fuente describe que la crisis financiera mundial, profundizada en septiembre del año 2008, su impacto en el Perú fue en el primer semestre del año 2009 en una menor demanda global de productos primarios e industriales, y caída del precio de diversos commodities. En este contexto, se mostró un fuerte dinamismo del mercado interno, sumado el impulso industrial de las pequeñas y medianas empresas condujo a que el país, tuviera un crecimiento del $0.9 \%$ del PBI, si bien inferior al año 2008 (8.9\%), pero fue positivo frente al de otros países de la región latinoamericana. La pregunta que se formuló fue icómo se vio reflejada esta coyuntura (2009) dentro de la lista de Las 10,000 Empresas TOP del Perú? La tendencia observada en el periodo 2004-2008 mostró un crecimiento sostenido de las medianas empresas en el Perú, según nivel de facturación, un aumento moderado de la gran empresa y una contracción constante de la pequeña empresa. Era de esperar un cambio en dicha tendencia como respuesta a los efectos de una crisis económica a inicio del 2009, y que en comparación con el año 2008 el número de medianas empresas disminuyó en 554 de 7,099 a 6,545 ; mientras que la gran empresa se mantuvo estable, levemente aumentó en 13 alcanzando un total de 913 empresas y las pequeñas empresas dentro de las TOP 10,000 se incrementaron en 541 de 2,001 a 2,542 compañías, como se puede apreciar en el siguiente cuadro: 
Cuadro N. ${ }^{\circ}$ 024: Principales empresas del año 2009-2008

\begin{tabular}{|c|c|c|c|c|}
\hline PRINCIPALES EMPRESAS (2009) & VALOR (soles) & VALOR (dólares-1) & $\begin{array}{l}2009 \\
\left(\mathrm{~N} .0^{\circ}\right)\end{array}$ & $\begin{array}{l}2008 \\
\left(\mathrm{~N} .{ }^{\circ}\right)\end{array}$ \\
\hline GRAN EMPRESA & Más de 70 millones & Más de 23.24 millones & 913 & 900 \\
\hline MEDIANA EMPRESA & De 6 a 70 millones & De 1.99 a 23.24 millones & 6545 & 7099 \\
\hline PEQUEÑA EMPRESA & De 400 mil a 6 millones ${ }^{2}$ & De 132 mil a 1.99 millones $^{2}$ & 2542 & 2001 \\
\hline TOTAL & & & 10000 & 10000 \\
\hline
\end{tabular}

La clasificación de las empresas se ha determinado en relación a su ingreso por venta facturada en el año 2009, estableciéndose los rangos siguiente:

Gran empresa: De S/. 70000000 a S/10 000000000

Mediana empresa: De S/. 6000000 a S/.70 000000

Pequeña empresa: De S/. 400000 a S/. 6000

De manera que se ha considerado como base para el presente estudio a 913 grandes empresas y que luego del análisis se determinó que 144 corresponden a las grandes empresas, resultando que 769 no participan (913-144). En este sentido, la población potencial para acceder al mercado ascendería a 769 empresas, es decir el 84\% del total de las grandes empresas.

De la población potencial de 769 grandes empresas, se determinó la muestra de 35 empresas. El cálculo determina un margen de error del $10 \%$, nivel aceptado:

$\mathrm{N}=769$ (Número de empresas=población)

Nivel de confianza $=0.9$ (90\% de confianza)

Acum $=0.95->\mathrm{Z}=1.64485363$ (zeta tabular)

$\mathrm{B}=0.1(10 \%$ margen de error máximo permitido en la estimación)

$\mathrm{p}=0.84$ (Proporción o probabilidad de éxito). La muestra de las 35 empresas comprende 12 empresas de rango superior, 11 de rango intermedio y 12 de rango inferior del ranking de las 769 empresas que no participan del mercado.

Descritos los rasgos de la problemática del mercado de valores en el Perú, se resume el planteamiento del problema a través de la interrogante ¿A qué se debe el déficit de activos financieros en el mercado de valores del Perú? y se establece como objetivo "describir por qué las deficiencias estructurales de la oferta de activos financieros en el mercado de valores del Perú están relacionadas a la limitada participación de empresas que ofertan instrumentos financieros" conllevando a determinar como principal hipótesis de estudio: "La deficiente regulación y promoción del Mercado de Valores del Perú contrae el acceso de empresas a este mercado", por lo que la investigación se centra en las interrogantes ¿A qué se debe el déficit de activos financieros en el mercado de valores del Perú? y ¿Por qué no participan las grandes empresa que tienen condiciones económicas y financieras que demanda el mercado? y será materia de estudio.

Con el propósito de comprobar la hipótesis, propuesta en el presente diseño de investigación, utilizaremos la información documental, bibliográfica y estadística que se obtendrá de las instituciones públicas, privadas y centros de información empresarial y de mercados, destacando la aplicación de encuestas y entrevistas a gerentes o alto ejecutivo de las empresas, considerando el análisis estadístico de los datos e información del mercado primario y secundario durante el periodo 2000 al 2009. En relación al cuestionario aplicado a las empresas, se destaca las siguientes interrogantes: ¿Por qué no participa del mercado de valores? ¿Tiene conocimientos de los beneficios, ventajas que ofrece el mercado de valores? ¿Qué le motivaría para ingresar al mercado de valores? ¿Qué le recomendaría, al Gobierno - EX CONASEV para acceder al mercado de valores? La medición y análisis de resultados se realizará a través de la aplicación de la estadística descriptiva, mediante programas estadísticos como el Minitab 16, SPSS y Excel, también se recurrirá a técnicas estadísticas inferenciales de ser necesario para la comprobación de las hipótesis. 
Acerca del marco teórico, se sustenta en conceptos de mercados y su relación con el comportamiento de la oferta y demanda, donde se destaca la relación riesgos y rentabilidad, por lo que resulta importante destacar la teoría del Portafolios y la Diversificación, como referencia.

El principal objetivo de la construcción de portafolios es lograr la diversificación del riesgo, explicado mediante la siguiente ilustración: supongamos que un inversionista posee solo una acción, la que se llamará empresa $\mathrm{A}$, ¿A qué riesgos se ve enfrentado dicho inversionista? dos fuentes de riesgo; en primer lugar se pueden considerar todos los riesgos que provienen de factores macroeconómicos, como la inflación, los ciclos económicos, etc., todos estos factores influyen en el desempeño de la acción y de todas las empresas en el mercado, y no existen mecanismos para poder predecirlos. En segundo lugar, existe una serie de riesgos propios de la empresa, como sus resultados, nuevos negocios, su capacidad emprendedora, etc. Estos factores afectan a la empresa $\mathrm{A}$ sin tener un impacto mayor en el resto de las empresas de la economía. Si se considera que el inversionista ahora agrega a su portafolio una segunda acción, como la empresa $\mathrm{B}$, el riesgo que posee su portafolio tendrá ahora el mismo riesgo macro que antes, pero mientras más se diferencien los riesgos específicos de las distintas empresas, la diversificación disminuirá el riesgo del portafolio, es decir el precio del principal producto de la empresa A puede caer, lo que afecta negativamente a sus resultados; mientras que el precio de productos de la empresa B puede subir, favoreciendo sus resultados. Los dos efectos se compensan, disminuyendo la volatilidad total del portafolio. Al agregar más acciones al portafolio, cada vez se podrá tener un riesgo menor dado que los riesgos específicos se compensarán (como en el ejemplo anterior). El límite para la reducción serán los factores macro que afectan a todas las empresas, es decir si todas las empresas están influidas por el ciclo económico, no se podrá eliminar ese riesgo. Estos riesgos son conocidos como riesgo sistémico o no diversificable y los riesgos no sistémico o diversificable (riesgo específico de la empresa). Este análisis se observa en el mercado o de modo empírico, donde se demuestra que el riesgo del portafolio se reduce con la diversificación.

En la elección de las inversiones y su relación con el riesgo conocido como selección de portafolio hay numerosos autores que han contribuido con esta teoría como Sharpe, Tobin, Miller y Modigliani pero destaca MARKOWITZ, nacido en Chicago en 1927, que ha dedicado una buena parte de su vida a la aplicación de métodos matemáticos y computacionales a la resolución de problemas reales, con especial atención a los problemas de naturaleza empresarial. Ha publicado numerosos libros y artículos, quizá los dos trabajos más relacionados con el tema son: "The Utility of Wealth", 1952, JPE; y "Portafolio Selection", 1952, J. of Finance. En ellos se asume que los rendimientos de una acción o cartera de valores sigue una distribución logaritmo-normal, que "podríamos aproximar" por una normal. La distribución normal se comporta conforme a la famosa "Campana de Gauss". Markowitz estudió las carteras e inversiones eficientes, es decir, aquellas, que sin renunciar a una rentabilidad mínima esperada, minimizan la desviación (el riesgo). Probó que se trata de inversiones muy diversificadas, es decir, que incorporan gran cantidad de activos en la cartera (A. Balbas - R.A.C.E, 2008). En cuanto a la selección de carteras, Sharpe y Tobin también hacen importantes aportes, como también las contribuciones de Miller y Modigliani, concepto clave es el estudio económico de los mercados de capitales. A Markowitz, le corresponde el mérito del desarrollo del modelo de media-varianza que constituye un intento pionero de enfocar la demanda de activos con riesgo. A Sharpe y a Miller y Modigliani se debe, entre otras contribuciones, al equilibrio de los mercados de capitales. Se relaciona el riesgo, rendimiento esperado y diversificación.

El segundo gran aporte del economista William Sharpe, nacido en 1934, fue que en 1964 publicó el famoso modelo CAPM (Capital Asset Pricing Model, o Modelo de Valoración de Activos de Capital) y que compartió con Markowitz y con Merton Miller el Premio Nobel de Economía en 1990. En el CAPM Sharpe sigue admitiendo que la desviación típica es una buena medida del riesgo, pero divide el riesgo total de una inversión en suma de dos, el riesgo de mercado y el riesgo específico. El segundo se puede eliminar sin renunciar a un beneficio esperado, siempre que cambiemos la inversión por otra apropiada y bien diversificada.

Contemporáneos de Sharpe que le influyeron de forma importante fueron, entre otros, Lintner, Tobin y Treynor. Pero mención especial es Stephen Ross, famoso para los economistas financieros por 
su modelo APT (Arbitrage Pricing Theory o Teoría de la Valoración por Arbitraje). En su modelo APT Ross extiende parcialmente el modelo de Sharpe, pues, aunque no llega a ningún tipo de equilibrio, el papel del mercado es sustituido por otros factores económicos (inflación no anticipada, precio del petróleo, paridad en tipos de cambio, etc.). Así, el riesgo, que sigue medido por la desviación típica, se descompone en el que es causado por cada uno de los factores más el específico. Esto permite diversificar el riesgo de las carteras de acuerdo a los factores explicativos de la economía (Szigethi, Jaime).

Toda la Teoría anterior sobre el Riesgo, medido por la desviación típica, ha sido extendida a nuestros días. Un concepto importante, es el de Factor de Descuento Estocástico (Stochastic Discount Factor), que el lector interesado podrá encontrar en los manuales de Economía Financiera que abordan el problema desde una perspectiva de profunda modelización matemática.

Como referencia los derivados en la valoración de activos y medición de riesgos, destacan los profesores Robert C. Merton, de la Universidad de Harvard, y Myron S. Scholes de la Universidad de Stanford, que fueron galardonados con el Premio Nobel de Economía por su trabajo en colaboración con Fischer Black, quien había muerto dos años antes. Conjuntamente habían desarrollado una metodología pionera para la valoración de activos financieros derivados, que posteriormente se había mostrado como una herramienta extraordinariamente potente a la hora de abordar otros muchos problemas financieros, como por ejemplo la gestión de riesgos. Los activos derivados, entre los que destacan los futuros financieros, que nos permiten fijar el precio de transacciones futuras, bien de activos financieros bien de mercancías, y las opciones, que nos permiten poner cotas a los precios de compras o ventas futuras, son instrumentos muy apropiados para la gestión de riesgos, ya que nos dan una oportunidad para adelantarnos a posibles evoluciones negativas de aquellos activos o bienes que vamos a comprar o vender más adelante. Pero su valoración era un tema muy complejo en la época de BlackMerton-Scholes que los tres autores anteriores resolvieron mediante la utilización de una nueva y muy innovadora metodología: Modelizaron el comportamiento dinámico de los precios y llegaron a una serie de ecuaciones nada fáciles de resolver. El aporte importantes del análisis de Black-Merton-Scholes es que el riesgo de una cartera de derivados se debe medir por las sensibilidades de su precio, y no por la desviación típica de su rentabilidad. Estas sensibilidades nos dicen cuánto va a variar el valor de nuestro patrimonio o cartera por unidad de cambio en las cotizaciones de mercado. Los gestores del riesgo deberán controlar el valor de las medidas de riesgo, y mantenerlas tan cerca de cero como les sea posible, negociando adecuadamente los activos disponibles en los mercados de capitales.

\section{Mercados financieros en el Perú y riesgos}

Los mercados financieros son ámbitos determinados por la oferta y la demanda de "Instrumentos financieros" como medios representativos de dinero y de capitales, los mismos que son transados entre agentes superavitarios (con excedentes) y deficitarios (con necesidades). Transacciones que determinan el valor o precio de los instrumentos, expresado en diferentes tasas y que están directamente determinados por el riesgo percibido de los agentes que intervienen en las transacciones. El mercado se caracteriza por la libre elección de la oferta y la demanda, transparencia, amplio, abierto e integrado.

En las transacciones financieras se originan obligaciones y derechos para quienes intervienen, como personas naturales, empresas y gobiernos producto de sus inversiones, préstamos o depósitos de ahorros de capitales, durante un cierto período de tiempo. También se originan diferentes denominaciones, como los activos financieros que se relacionan a las posesiones y que se diferencian de las inversiones en activos reales, porque estas últimas corresponden a bienes de capital-físico para actividades productivas de bienes o productos. Si los ahorros fueran iguales a la inversión de todas las unidades económicas en un país durante todo tiempo, no habría financiación externa, no existirían activos financieros o instrumentos financieros y no tendrían importancia el mercado monetario ni el mercado de capitales.

En una economía como un todo, se suministran fondos de unidades económicas llamadas "superávit", cuyos ahorros exceden sus inversiones en activos reales, a unidades "Deficitarias", cuya inversión en activos reales excede sus economías. Este intercambio de fondos se evidencia por medio de papeles que representan un activo financiero para el que tiene o posee y una obligación financiera para el que emite, desarrollándose así 
el proceso de Ahorro-Inversión, a través de mercados denominados de capitales.

Dada la elevada competitividad y el desarrollo de la tecnología de las telecomunicaciones, el objetivo de los mercados financieros en una economía es asignar eficientemente los ahorros a los usuarios finales. Una economía podría prosperar sin mercados financieros, si aquellas unidades económicas que ahorran fueran las mismas que estuvieran involucradas en la formación de capital. En las economías modernas, sin embargo, las unidades económicas responsabilizadas en mayor grado para la formación de capital, invierten en activos reales en una cuantía que está por encima de sus ahorros totales. Las familias por otro lado, tienen ahorros totales que están por encima de sus inversiones, es así que a mayor diversidad de los patrones de los ahorros deseados y de las inversiones entre las unidades económicas, será mayor la necesidad para tener mercados financieros eficientes que canalicen los recursos de las economías al menor costo posible y/o inconveniencia para los dos.

Los mercados permiten la interconexión de los ofertantes y demandantes de recursos e instrumentos financieros a través de Instituciones, normas, costumbres y prácticas de personas que intervienen en la canalización de recursos financieros, surgiendo así las regulaciones y el Sistema Financiero. Es así que las transacciones de diversos instrumentos determinan "los activos y pasivos financieros" y se desarrollan mediante la intermediación de dinero y de capitales que conforman los mercados financieros. La intermediación se desarrolla en dos mercados: Mercado de dinero y de capitales, este último se viene desarrollando a través de derivados y futuros. Desagregación descrita en siguiente esquema:

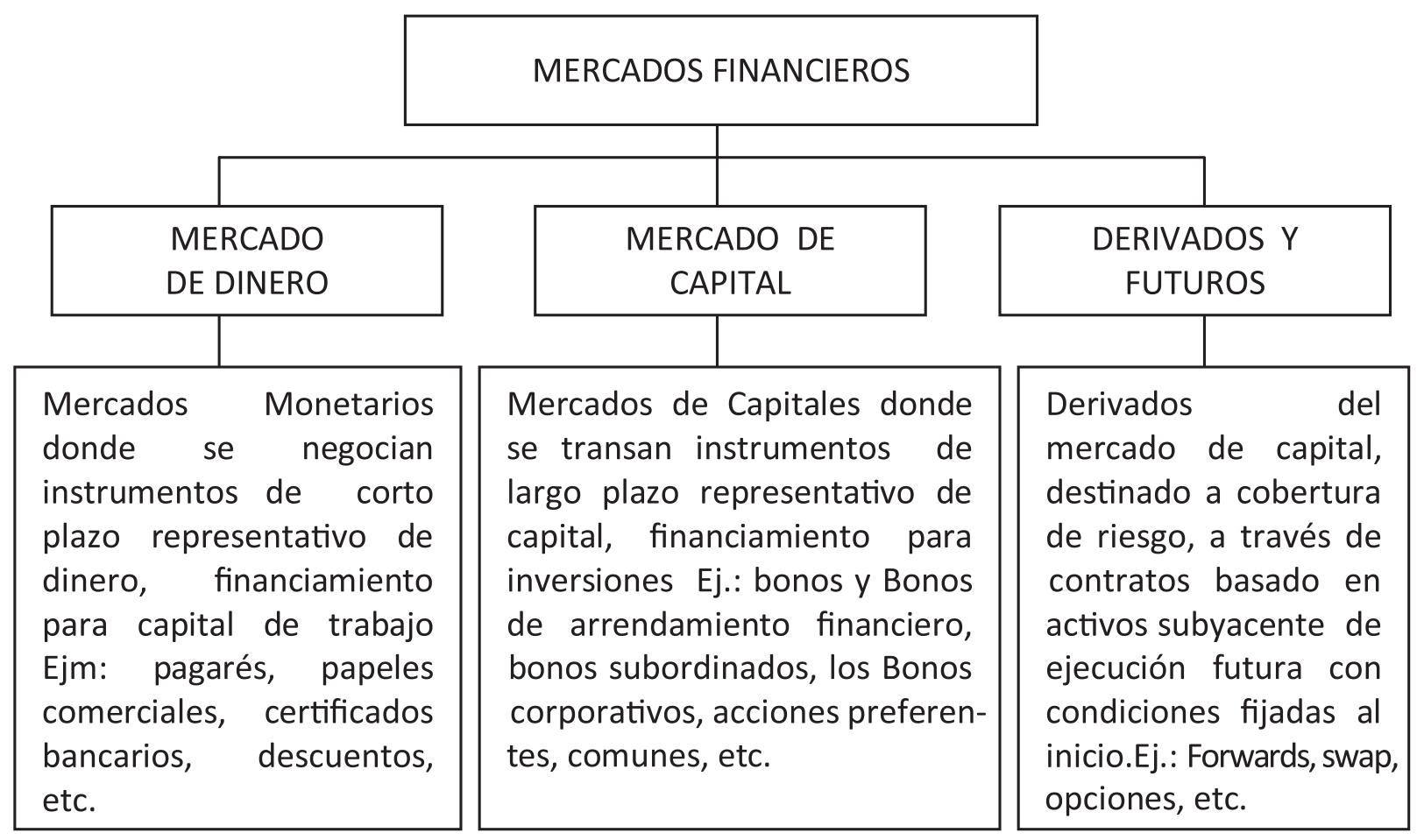

El Sistema Financiero Nacional está conformado por las instituciones reguladoras, supervisoras e intermediarios, comprendiendo a los mercados de dinero y mercados de capitales, impulsados por el mercado de valores.

Respecto al mercado de dinero en nuestro país, este se ha venido impulsando por la Banca Extranjera, propiciando mayor competencia, mayor intermediación tanto de depósitos de ahorros como créditos bancarios a nivel nacional, reflejado en diferentes tasas de interés o costo del dinero. Las tasas han venido descendiendo pero aun son altas en comparación con las tasas internacionales. Así la tasa de interés promedio en moneda nacional- TAMN (soles) de 135\% en 1992 desciendo a $22.91 \%$ en el 2009 y la tasa promedio en moneda extranjera- TAMEX (dólares) de 16.90\% en 1992 desciendo a $10.30 \%$ en el 2009 , y a $19.50 \%$ en soles a julio 2012. Evolución de 1992 al 2012, se puede observar en los cuadros siguientes: 
Cuadro N. ${ }^{\circ}$ 05. Tasas de interés en el Sistema Financiero Nacional 1992-2009

\begin{tabular}{|c|c|c|c|}
\hline \multicolumn{4}{|c|}{ DIFERENCIA DE LAS TASAS DE INTERÉS } \\
\hline ACTIVAS EN SOLES Y EN DÓLARES & TAMEX & DIF(spread) \\
\hline AÑO & TAMN & $16.90 \%$ & 56.30 \\
\hline 1992 & $135.50 \%$ & $15.20 \%$ & 23.80 \\
\hline 1993 & $71.50 \%$ & $15.20 \%$ & 17.90 \\
\hline 1994 & $39.00 \%$ & $17.20 \%$ & 13.26 \\
\hline 1995 & $35.10 \%$ & $16.80 \%$ & 14.44 \\
\hline 1996 & $30.06 \%$ & $15.60 \%$ & 15.53 \\
\hline 1997 & $30.04 \%$ & $16.80 \%$ & 17.87 \\
\hline 1998 & $32.33 \%$ & $14.46 \%$ & 12.92 \\
\hline 1999 & $32.33 \%$ & $12.06 \%$ & 8.61 \\
\hline 2001 & $24.98 \%$ & $12.16 \%$ & 10.98 \\
\hline 2002 & $20.77 \%$ & $10.04 \%$ & 15.13 \\
\hline 2003 & $21.02 \%$ & $9.66 \%$ & 16.35 \\
\hline 2004 & $24.79 \%$ & $9.07 \%$ & 13.53 \\
\hline 2005 & $25.42 \%$ & $9.86 \%$ & 12.33 \\
\hline 2006 & $23.39 \%$ & $10.54 \%$ & 13.05 \\
\hline 2007 & $22.87 \%$ & $10.63 \%$ & 12.61 \\
\hline 2008 & $23.68 \%$ & $10.30 \%$ & \\
\hline $\left.2009{ }^{*}\right)$ & $22.91 \%$ & & \\
\hline 2009 Fuente BCRP & & & \\
\hline * Marzo del & & & \\
\hline
\end{tabular}

ELEVADOS MÁRGENES EN MONEDA NACIONAL PERIODO 1992-2012

\begin{tabular}{|c|c|c|c|}
\hline AÑO & TAMN & TIPMN & SPREAD \\
\hline 1992 & $135,50 \%$ & $18,15 \%$ & $117,35 \%$ \\
1993 & $71,50 \%$ & $18,20 \%$ & $53,30 \%$ \\
1994 & $39,00 \%$ & $7,30 \%$ & $31,70 \%$ \\
1995 & $35,10 \%$ & $9,90 \%$ & $25,20 \%$ \\
1996 & $30,06 \%$ & $10,50 \%$ & $19,56 \%$ \\
1997 & $30,04 \%$ & $9,90 \%$ & $20,14 \%$ \\
1998 & $32,06 \%$ & $12,60 \%$ & $19,46 \%$ \\
1999 & $32,33 \%$ & $10,49 \%$ & $21,84 \%$ \\
2000 & $32,33 \%$ & $9,70 \%$ & $22,63 \%$ \\
2012 ( $)^{*}$ & $19,50 \%$ & $2,50 \%$ & $17,00 \%$ \\
\hline
\end{tabular}

(*) Al 11 de Julio del 2012. Fuente: SBS

Respecto al mercado de valores en el Perú, resulta incipiente y deficitario en instrumentos financieros pero a diferencia del mercado de dinero, resulta débil, se caracteriza por el elevado riesgo y volatilidad que experimentan las cotizaciones de los instrumentos que se negocian, al estar expuesto no solo a los riesgos operativos de la empresa sino a los de mercado tanto interno como externo. No obstante que las condiciones del mercado propician bajo costo de endeudamiento para la Inversión real, hay poca participación de empresas y ante el aumento de la demanda se produce exceso de liquidez, aun en la actualidad. Tal importante déficit de oferta, como referencia se puede apreciar en el siguiente esquema de oferta y demanda en el 2005.
ELEVADOS MÁRGENES EN MONEDA EXTRANJERA PERIODO 1992-2012

\begin{tabular}{|c|c|c|c|}
\hline AÑO & TAMEX & TIPMEX & SPREAD \\
\hline 1992 & $16.90 \%$ & $5.78 \%$ & $11.12 \%$ \\
1993 & $15.20 \%$ & $5.00 \%$ & $10.20 \%$ \\
1994 & $15.20 \%$ & $4.90 \%$ & $10.30 \%$ \\
1995 & $17.20 \%$ & $6.20 \%$ & $11.00 \%$ \\
1996 & $16.80 \%$ & $5.70 \%$ & $11.10 \%$ \\
1997 & $15.60 \%$ & $5.20 \%$ & $10.40 \%$ \\
1998 & $16.80 \%$ & $5.40 \%$ & $11.40 \%$ \\
1999 & $14.46 \%$ & $4.84 \%$ & $9.62 \%$ \\
2000 & $12.46 \%$ & $4.60 \%$ & $7.86 \%$ \\
$2012\left(^{*}\right)$ & $8.07 \%$ & $0.83 \%$ & $7.24 \%$ \\
\hline
\end{tabular}

En el crecimiento de la demanda, se debe a fondos de pensiones a través de las Administradoras de Fondos de Pensiones, operaciones que empezaron en 1993. En cuanto a las restricciones en títulos de sociedades anónimas, existe como máximo 35\% invertir en bonos de estas entidades. Sin embargo, las colocaciones conjuntas en acciones (tanto comunes como del trabajo) más Certificados de Suscripción Preferente, Operaciones de Reporte, Productos Derivados y Cuotas de Fondos Mutuos no pueden sobrepasar el 30\% de las inversiones. Lo más destacable esta en permitirle invertir en el exterior hasta 50\% como límite legal, y como límite operativo de inversión en el exterior fijado por el BCRP, es de $32 \%$ en la actualidad (Enero 2013). 


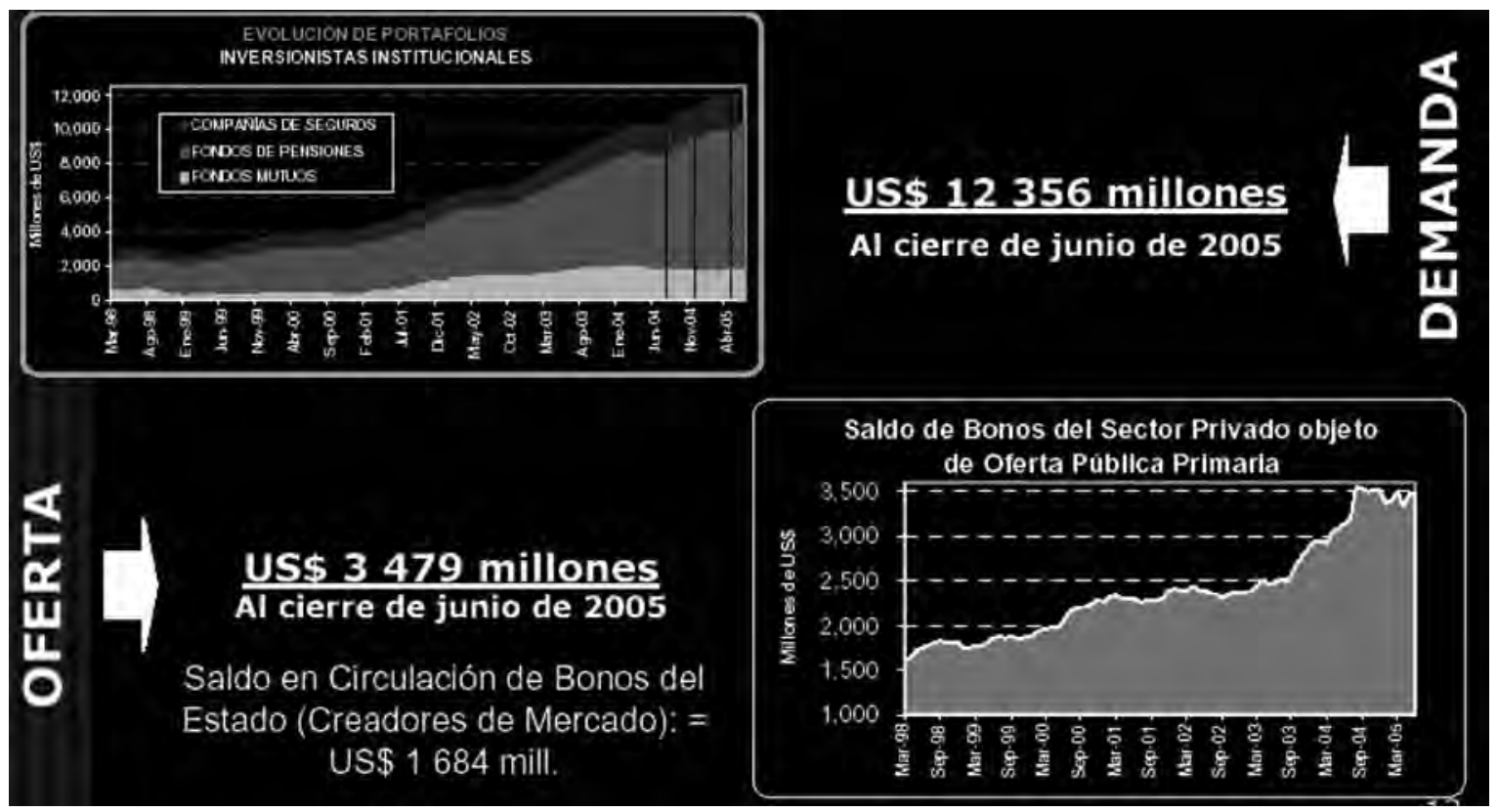

Aparte de las limitaciones descritas, se aprecia restricciones en el acceso a este mercado, explicado por la mayoría del empresariado peruano con solvencia económica y financiera, no participa del mercado de valores para financiarse, como se observa en las 769 grandes empresas, a diferencia de otras economías que sí utilizan su mercado con mucha regularidad. Sin embargo el desempeño del Mercado de Valores Peruano ha sido favorable no solo por el aumento de sus operaciones sino por su notable rendimiento de sus valores, particularmente del mercado accionario (Bolsa de Valores de Lima-BVL).

El entorno del mercado, describe factores negativos, donde se destaca la falta de eficiencia en la Administración Pública, debilidades en la administración de justicia; presencia de grupos de presión; corrupción por lo que es necesario minimizar estos riesgos para contribuir a que el Perú sea atractivo para la inversión de largo plazo y para impulsar el mercado de valores. Además hay elevado costo en las emisiones, como algo más del 3\% de costo requerido para un monto de emisión de 5 millones de dólares para bonos, lo que hace muy difícil la participación en el mercado de valores a empresas medianas y pequeñas. Por lo resulta necesario explorar medidas para superar la escasa participación de grandes empresas, mejorar la regulación y destacar las ventajas, beneficios para los inversionistas y para el sector empresarial. Con todos factores referidos, el mercado de Emisiones-Primario ha venido creciendo desde 1992, como se puede observar en el siguiente cuadro:

Cuadro N. ${ }^{\circ}$ 06. Valores inscritos vs. Colocados. Mercado Primario 1992-2009

\begin{tabular}{|l|c|c|c|c|c|c|c|c|c|c|c|c|c|c|c|c|c|c|}
\hline US\$ M M & 1992 & 1993 & 1994 & 1995 & 1996 & 1997 & 1998 & 1999 & $\mathbf{2 0 0 0}$ & $\mathbf{2 0 0 1}$ & $\mathbf{2 0 0 2}$ & $\mathbf{2 0 0 3}$ & $\mathbf{2 0 0 4}$ & $\mathbf{2 0 0 5}$ & $\mathbf{2 0 0 6}$ & $\mathbf{2 0 0 7}$ & $\mathbf{2 0 0 8}$ & $\mathbf{2 0 0 9}$ \\
\hline INSCRITO & 10 & 20 & 95 & 340 & 849 & 1644 & 1092 & 817 & 1539 & 1867 & 1218 & 1759 & 2060 & 2086 & 3084 & 3944 & 4864 & 7046 \\
\hline COLOCADO & 10 & 20 & 92 & 315 & 770 & 1376 & 590 & 569 & 1014 & 1096 & 828 & 1451 & 1248 & 1474 & 1565 & 1670 & 1411 & 1710 \\
\hline $\begin{array}{l}\text { COL / INSC. } \\
\text { (\%) }\end{array}$ & $100 \%$ & $100 \%$ & $97 \%$ & $93 \%$ & $91 \%$ & $84 \%$ & $54 \%$ & $70 \%$ & $66 \%$ & $59 \%$ & $68 \%$ & $82 \%$ & $61 \%$ & $71 \%$ & $51 \%$ & $42 \%$ & $29 \%$ & $24 \%$ \\
\hline
\end{tabular}

Fuente: Registro Público del Mercado de Valores - CONASEV 
El mercado de valores peruano pese a lo incipiente, su mercado primario ha venido describiendo un incremento en las emisiones, valores inscritos que son colocados gradualmente, por lo que la demanda siempre supera a lo oferta, determinándose el déficit de instrumentos financieros, referido. Evolución ascendente se podrá observar en el siguiente gráfico:

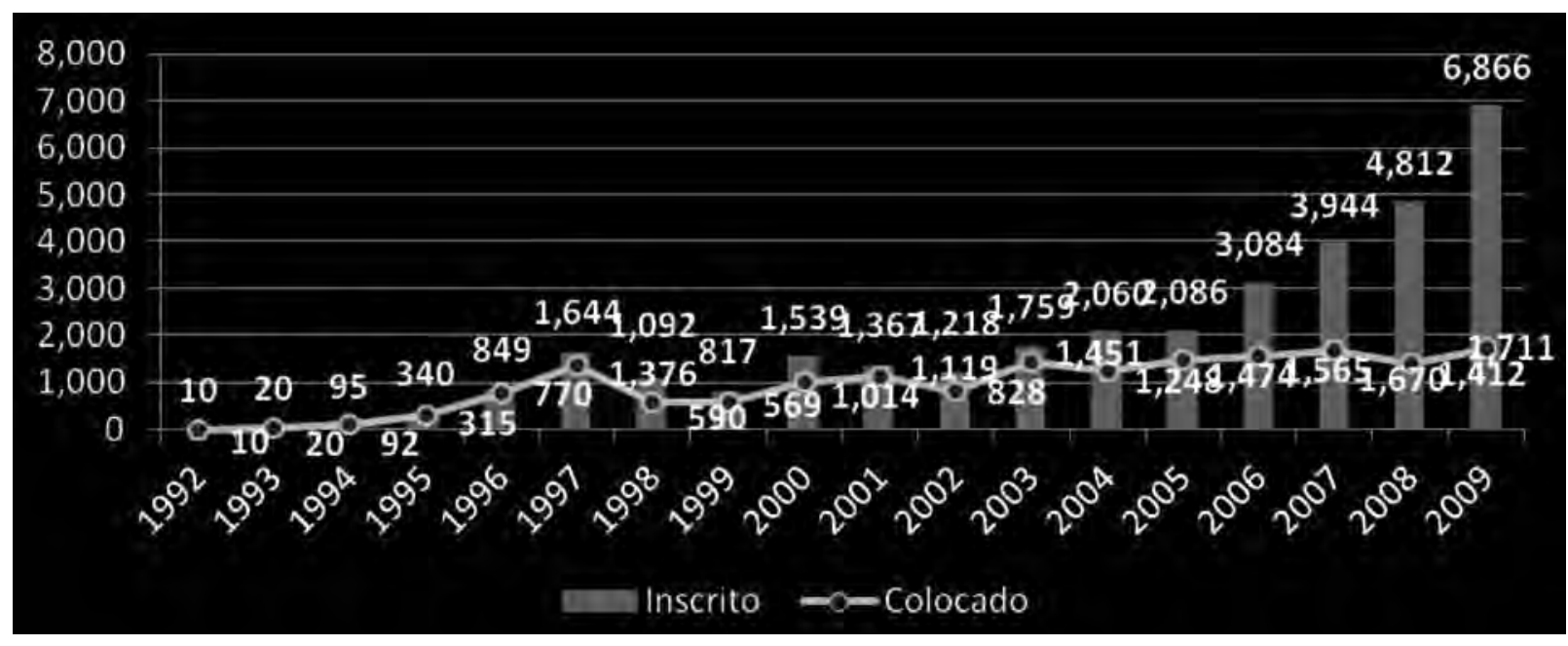

El mercado de capitales es esencial para el desarrollo económico del País, por ofrecer diferentes mecanismos e innumerables instrumentos financieros a los agentes económicos que demandan inversiones de largo plazo necesario para atender necesidades productivas, infraestructura, tecnologías, etc., movilizando el dinero en exceso (ahorros o inversionistas) al sector real de la economía. Como es sabido, por medio de una mayor propensión al ahorro, se genera una mayor inversión, debido a que se producen excedentes de capital para los ahorradores, los cuales buscan invertirlos y generar mayor riqueza. Esta inversión da origen, a nuevas industrias generadoras de ingresos, siendo este el principal objetivo del mercado de capitales. Es el conjunto de mecanismos a disposición de una economía para cumplir la función básica de asignación y distribución en el tiempo, de los recursos de capital, los riesgos, el control y la información asociados con el proceso de transferencia del ahorro a inversión, desatacando en este mercado de capitales, la Bolsa de Valores, considerado termómetro de la Economía, importante información por revelar y descontar flujos futuros de ingresos y expectativas, surgiendo preocupación cuando las cotizaciones de los valores bajan ("signos de mercado").

Acerca de la regulación del mercado de valores en nuestro país, está a cargo de la Superintendencia del Mercado de Valores, dedicado a la supervisión y control del mercado de emisiones y bursátil. Para la evaluación de las emisiones se cuenta con empresas Clasificadoras de Riesgo, que en el Perú son cuatro, según el Reglamento de Empresas Clasificadoras de Riesgo en su Artículo 15 denominado Clasificación Obligatoria se estipula que "Las personas jurídicas que emitan por oferta pública valores representativos de deuda debe contratar los servicios de cuando menos dos (2) clasificadores, independientemente entre sí, para que efectúen la clasificación permanente de esos valores. Es facultad de SMV determinar aquellos valores que por sus características califican como representativos de deuda, en tales casos los valores deberán ser clasificados obligatoriamente.

Respecto a las operaciones en el mercado, se destaca que al 2010, solo participan 220 empresas (acciones y bonos), pocas a la elevada cantidad potencial de 769 grandes empresas que no participan. Considerando el número de empresas y fondos, ascienden a 263 al 2010 , levemente superior a las 254 en 1999. Desagregación que se aprecia en los siguientes cuadros:

Cabe señalar que el número de empresas (acciones y bonos) que participan al 2012 ascendió a 282 superior a 220 en el 2010, pero aun bajo en relación a la cifra de empresas potenciales de 769 y considerando el número de empresas y fondos con valores inscritos ascendieron a 320 en el 2012.

Respecto a la importancia del mercado secundario, Bolsa de Valores de Lima-BVL en relación al PBI es relativamente bajo, como el $4.7 \%$ en el 2009. Tal participación en el PBI, se puede apreciar en el siguiente gráfico: 


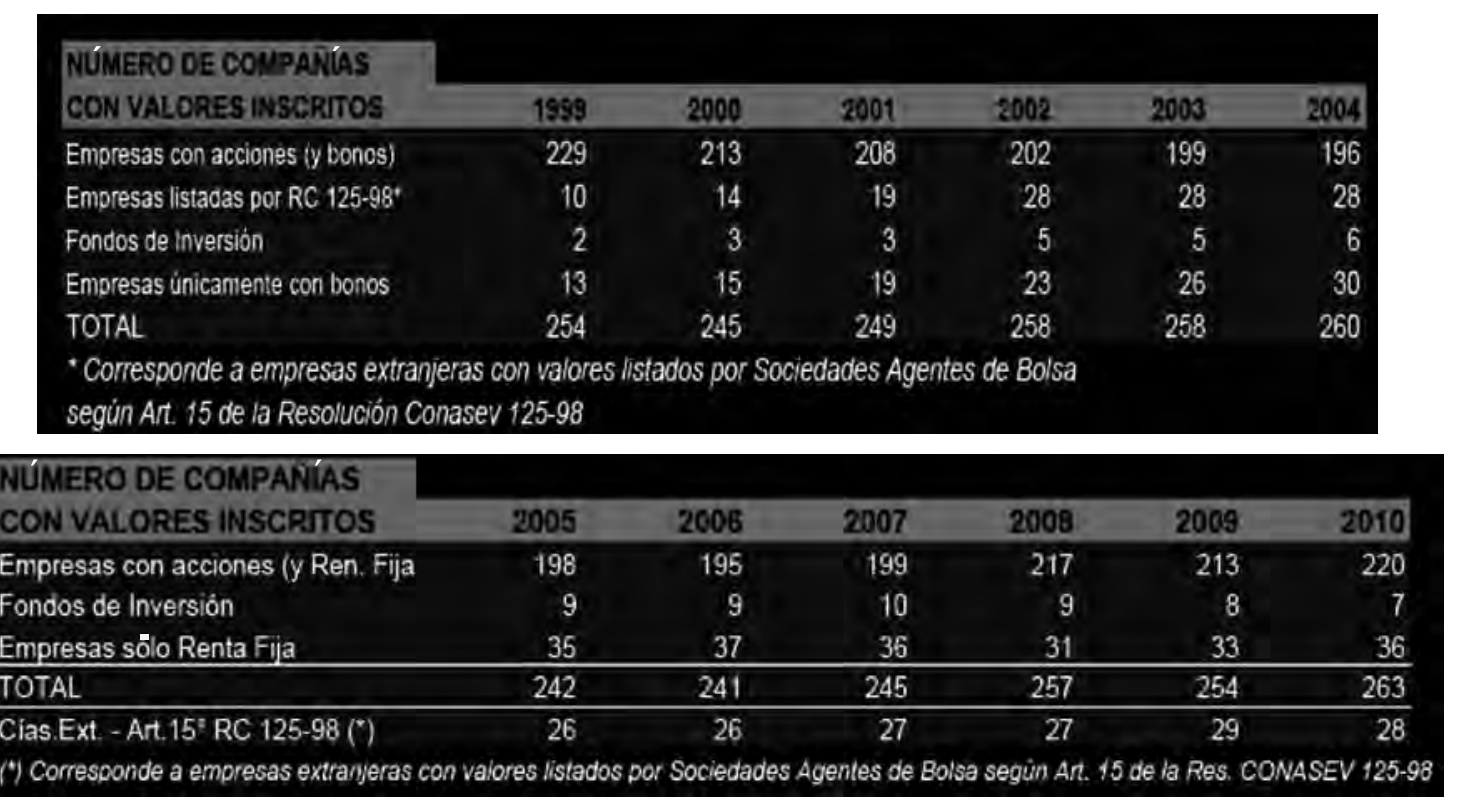

Fuente: Bolsa de Valores de Lima.

Mercado secundario como proporción del Producto Bruto Interno 2001- 2009.

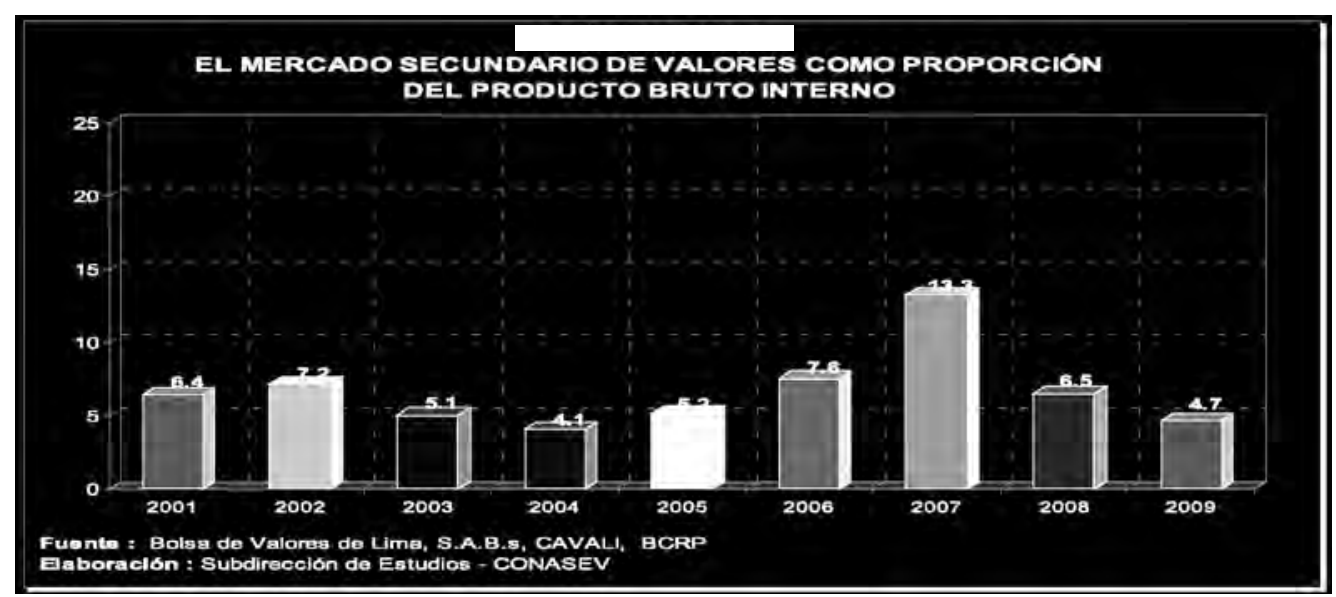

Fuente: Bolsa de Valores de Lima.

La negociación en la BVL ha venido en aumento, ya que de \$ 3,011 millones de dólares en el año 2001 se elevó a \$ 12,408 en el 2007, luego, ante el impacto de la crisis internacional descendió a \$ 5,677 en el 2009. Tales montos negociados se puede observar en el siguiente gráfico: Monto total negociado: 2001-2009.

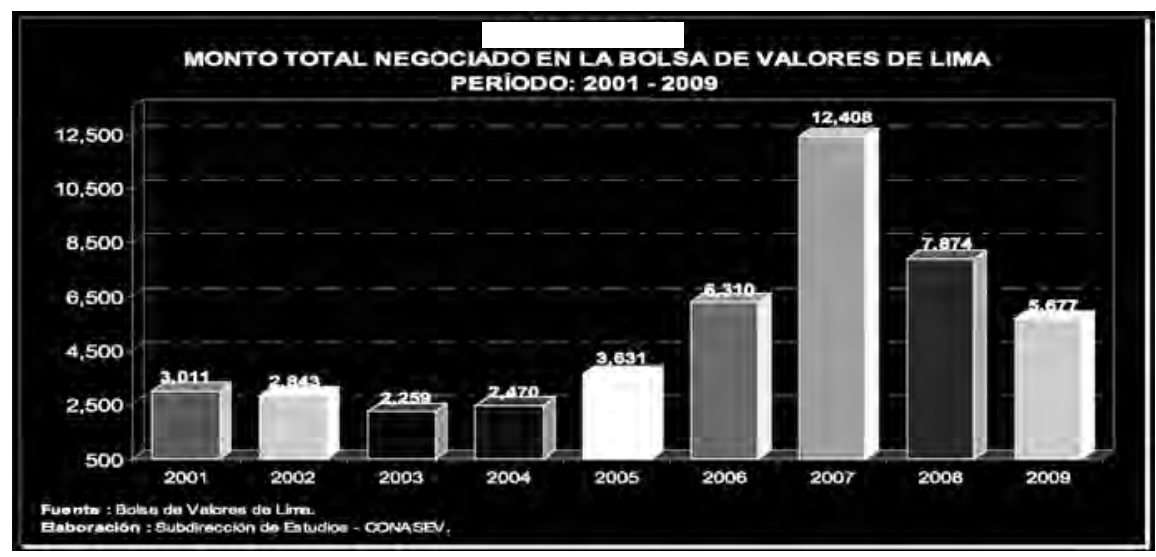

Fuente: Bolsa de Valores de Lima. 
Un indicador importante es la capitalización bursátil, relacionada al valor de mercado de las empresas, este ha venido incrementándose. Así en el 2005 de \$ 36.195.91 millones de dólares pasó a \$ 160.867.45 millones en el 2010, pese a la caída en el 2008 que fue de \$ 57.231.44 millones. Tal capitalización bursátil se puede observar en el siguiente gráfico: Capitalización Bursátil 2005 - 2010.

\begin{tabular}{|c|c|c|c|c|c|c|}
\hline IURSÁTIL & & & & & & \\
\hline Millones de Dólares & 2005 & 2006 & 2007 & 2008 & 2009 & 2010 \\
\hline Acciones de Capital & $34,347,05$ & $56,447.41$ & $104,002.63$ & $55,064.04$ & $103,673,79$ & $155,169,83$ \\
\hline A.F.P. & 152.78 & 251.96 & 260.06 & 230.05 & 543.08 & 153.17 \\
\hline Bancos y Financieras & $4,917.24$ & 8.814 .58 & $11,114.84$ & $7,316.23$ & $15,513.99$ & $20,166.01$ \\
\hline Industriales & 4.963 .27 & 4.160 .57 & $5,576.28$ & $2,953.12$ & $6,241,61$ & $9,172.78$ \\
\hline Mineras & $16,715.55$ & $32,039.75$ & $58,133.81$ & $28,957.85$ & $57,875,63$ & $90,546.37$ \\
\hline Seguros & 372.20 & 522.90 & $1,036.84$ & 527.62 & 936.48 & $1,565.21$ \\
\hline Agrario & 454.51 & 748.88 & $1,251.50$ & 627.09 & 843.52 & $1,383.48$ \\
\hline Servicios Püblicos & $3,330-14$ & $4,068.95$ & $11,932.44$ & $4,769.17$ & $7,814,43$ & $9,905,26$ \\
\hline Diversas & $3,441.36$ & $5,839.82$ & $14,696.86$ & $9,682.90$ & $13,905.05$ & $22,277.55$ \\
\hline Acciones de Inversión & 1.848 .86 & 3.572 .56 & $4,217.08$ & $2,167.41$ & $3,651.50$ & $5,697.62$ \\
\hline Industriales & 653.93 & 1.057 .69 & $1,399.05$ & 801.45 & $1,376,65$ & $2,220.99$ \\
\hline Mineras & $1,177.05$ & $2,491.10$ & $2,805.93$ & $1,349.64$ & $2,254: 19$ & $3,424.30$ \\
\hline Diversas & 17.88 & 23.77 & 12.10 & 16.32 & 20.66 & 52.33 \\
\hline CAPITALIZACION TOTAL BVL & $36,195,91$ & 60,01997 & 108.219 .71 & $57,231,44$ & $107,325,29$ & $160,867.45$ \\
\hline \% 10 valores con > capitalización & $69.75 \%$ & $68.31 \%$ & $69.63 \%$ & $69.56 \%$ & $71.20 \%$ & $70.91 \%$ \\
\hline
\end{tabular}

Cabe señalar que la capitalización bursátil al 2012, descendió a \$ 153.404.20 millones de dólares, inferior a \$ 160.867 .45 millones en el 2010.

Respecto a la Rentabilidad de la bolsa de valores, se puede destacar el impacto de los riesgos de mercados en las cotizaciones y por tanto en la rentabilidad. La BVL a través de la variación de la cartera del Índice General, ha venido describiendo una tendencia creciente y muy activa en relación al crecimiento del PBI, pero también respondiendo a la Crisis Internacional iniciada en el 2007, sin embargo ha descrito una elevada rentabilidad, como fue en el 2006 en que alcanzó el $187 \%$ (variación del IGBVL), siendo una de las bolsas más rentable del mundo. Cabe señalar la notable caída en el 2008 de $-61.52 \%$ debido a la crisis internacional aun vigente, aunque se viene recuperando rápidamente debido al alza de los minerales y al sostenido crecimiento de la economía de la China y al marco macroeconómico favorable. Rentabilidad que se puede observar en el siguiente cuadro: 2002 - 2009.

Cuadro N. ${ }^{\circ}$ 06: Rentabilidad de la Bolsa de Valores 2002 - 2009 (En US \$)

\begin{tabular}{|c|c|c|c|c|c|c|c|c|}
\multicolumn{1}{c}{} & \multicolumn{2}{c}{2002} & 2003 & \multicolumn{2}{c}{2004} & 2005 & 2006 & 2007 \\
\hline Perú Selectivo 15 & $13.65 \%$ & $71.74 \%$ & $70.00 \%$ & $18.00 \%$ & $216.00 \%$ & $52.00 \%$ & $-61.27 \%$ & $107.89 \%$ \\
\hline Perú IGBVL & $16.28 \%$ & $76.34 \%$ & $61.00 \%$ & $24.56 \%$ & $186.92 \%$ & $45.55 \%$ & $-61.52 \%$ & $117.75 \%$ \\
\hline Perú ISBVL & $12.89 \%$ & $82.81 \%$ & $63.00 \%$ & $20.01 \%$ & $208.52 \%$ & $40.22 \%$ & $-61.48 \%$ & $107.89 \%$ \\
\hline China Shangai & $-9.39 \%$ & $10.31 \%$ & $-15.00 \%$ & $-6.00 \%$ & $138.00 \%$ & $30.00 \%$ & $-63.03 \%$ & $79.86 \%$ \\
\hline Chile IPSA & $49.82 \%$ & $76.59 \%$ & $29.00 \%$ & $20.00 \%$ & $34.00 \%$ & $13.00 \%$ & $-37.18 \%$ & $84.56 \%$ \\
\hline Brasil Bovespa & $0.42 \%$ & $141.49 \%$ & $28.00 \%$ & $49.00 \%$ & $45.00 \%$ & $12.00 \%$ & $-55.07 \%$ & $144.19 \%$ \\
\hline Alemania DAX & $8.99 \%$ & $66.18 \%$ & $16.00 \%$ & $11.00 \%$ & $35.00 \%$ & $11.00 \%$ & $-43.35 \%$ & $26.93 \%$ \\
\hline México Mexbol & $24.33 \%$ & $32.52 \%$ & $48.00 \%$ & $44.00 \%$ & $45.00 \%$ & $10.00 \%$ & $-39.76 \%$ & $50.30 \%$ \\
\hline Francia CAC & $-8.69 \%$ & $39.63 \%$ & $16.00 \%$ & $8.00 \%$ & $30.00 \%$ & $6.00 \%$ & $-43.35 \%$ & $25.37 \%$ \\
\hline UK FTSE & $12.26 \%$ & $1.72 \%$ & $16.00 \%$ & $6.00 \%$ & $26.00 \%$ & $4.00 \%$ & $-6.42 \%$ & $10.71 \%$ \\
\hline USA Nasdaq & $16.22 \%$ & $50.50 \%$ & $9.00 \%$ & $2.00 \%$ & $10.00 \%$ & $3.00 \%$ & $-40.54 \%$ & $43.89 \%$ \\
\hline Japón Nikkei & $8.30 \%$ & $39.64 \%$ & $13.00 \%$ & $22.00 \%$ & $6.00 \%$ & $3.00 \%$ & $-27.40 \%$ & $14.91 \%$ \\
\hline Argentina Merval & $36.44 \%$ & $133.45 \%$ & $27.00 \%$ & $10.00 \%$ & $33.00 \%$ & $2.00 \%$ & $-55.03 \%$ & $97.13 \%$ \\
\hline USA Dow Jones & $10.27 \%$ & $24.98 \%$ & $3.00 \%$ & $0.00 \%$ & $16.00 \%$ & $1.00 \%$ & $-33.84 \%$ & $18.82 \%$ \\
\hline Colombia IGBC & $41.44 \%$ & $48.36 \%$ & $120.00 \%$ & $124.00 \%$ & $22.00 \%$ & $1.00 \%$ & $-36.56 \%$ & $68.82 \%$ \\
\hline
\end{tabular}

Fuente: Bolsa de Valores de Lima. 
La rentabilidad de la Bolsa de Lima, luego de la caída en el 2008, se recuperó en el 2009 alcanzando una rentabilidad del $117.75 \%$, sin embargo la rentabilidad descendió a -13. 21\% en el 2011 y levemente ascendió a 12\% en el 2012.

\section{Resultados y restricciones en el acceso al mercado}

Los resultados establecen que solo 144 grandes empresas participan en el mercado de valores peruano de un total 913, determinándose un potencial de 769 grandes empresas, es decir el $84 \%$ de las grandes empresas no participan en el mercado. Las restricciones en el acceso al mercado de valores del país, se describen en las respuestas brindadas por los altos ejecutivos, representantes de las grandes empresas encuestadas.

Los resultados predominantes relacionados a la hipótesis: "La deficiente regulación y promoción del Mercado de Valores del Perú contrae el acceso de empresas a este mercado". Se describen en las siguientes respuestas:

a) Solo el $26 \%$ de las grandes empresas están bien informadas del mercado de valores. El 29\% está algo informada, el $28 \%$ conoce muy poco sobre él y el $17 \%$ restante no tiene conocimiento. Descrito en gráfico siguiente:

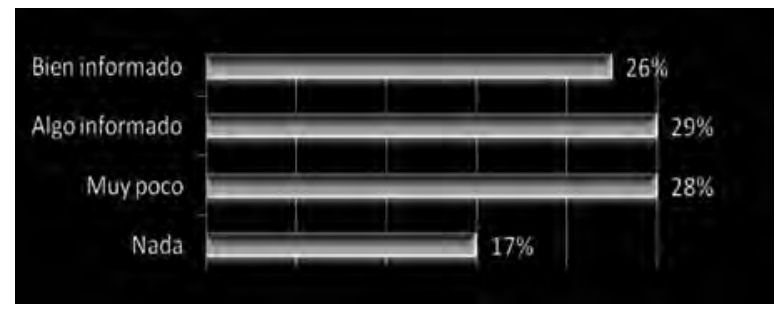

b) El $51.43 \%$ considera que sí se debe mejorar la difusión de la cultura del mercado de valores como buena motivación para ingresar al mercado. Descrito en gráfico siguiente:

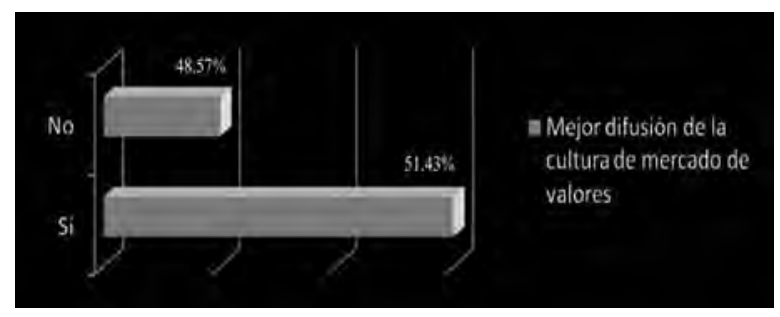

Los resultados relacionados a la hipótesis: "La disminución de costos financieros y la reducción de trámites burocráticos, originarán un mayor acceso al mercado de empresas nacionales, con lo cual aumentarán sus opciones de financiamiento de largo plazo" se describen en las siguientes respuestas: a) El 46\% de las grandes empresas sí conocen el mercado, pero no participan por los altos costos y por preferir no divulgar información de su empresa. Descrito en gráfico siguiente:

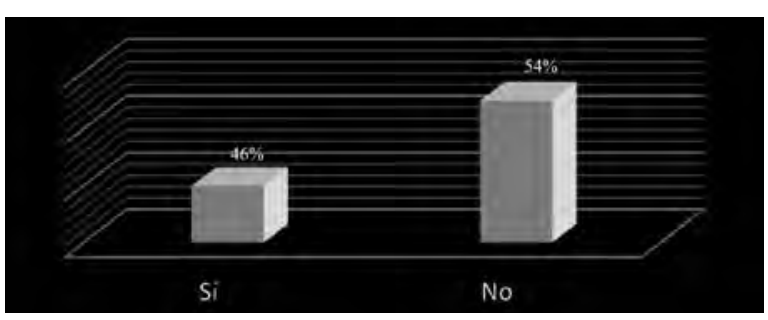

b) El $40 \%$ de las grandes empresas manifiestan que la regulación sí es engorrosa, por lo que no participan del mercado. Descrito en gráfico siguiente:

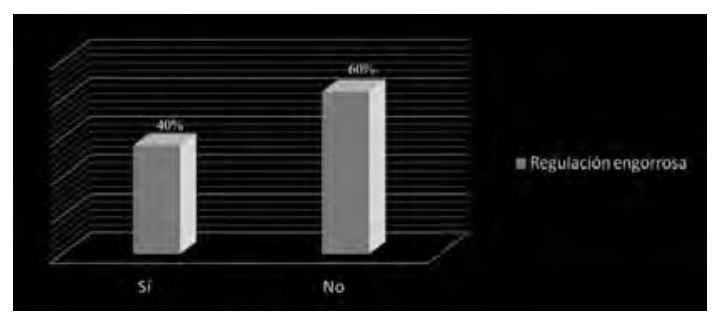

c) El 37.14\% de las grandes empresas manifiestan que sí se debe flexibilizar los requisitos, considerando como motivaciones para ingresar al mercado de valores. Descrito en el gráfico siguiente:

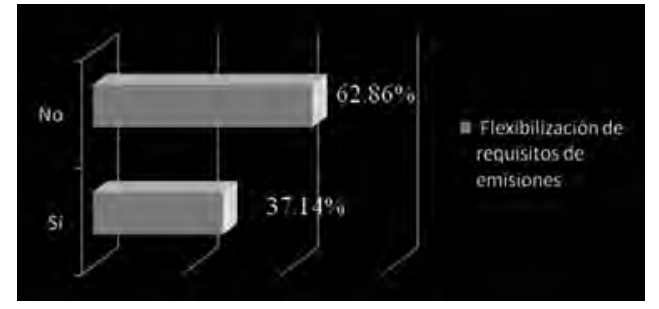

d) El 51\% manifiestan que sí se debe reducir los costos asociados a las emisiones. Descrito en el gráfico siguiente:

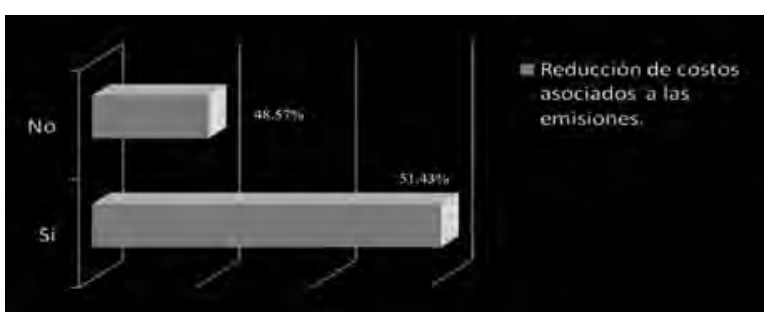

\section{DISCUSIÓN}

El análisis de los resultados obtenidos comprueban la hipótesis: "La deficiente regulación y promoción del Mercado de Valores del Perú contrae el acceso de las empresas a este mercado". Afirmación que observa la legislación vigente del 
mercado de valores al encarecer el costo de acceso de empresas a emitir bonos y acciones. La Ley de Mercado de Valores en los requisitos exigidos para las ofertas públicas primarias establece como la obligación de contar con una unidad estructuradora, un agente colocador y dos clasificadoras de riesgo, elevando los costos fijos de emisión de bonos corporativos, lo que hace que se requiera un monto mínimo de emisión de 5 millones de dólares para bonos, cuyo costo es algo más del 3\%

El resultado de la investigación destaca que el $46 \%$ de las grandes empresas no participan en el mercado de valores por los altos costos, el $40 \%$ no participan por la regulación engorrosa, el 37\% estarían motivadas a ingresar al mercado de valores con flexibilización de requisitos de las emisiones, el 51\% considera que se debe mejorar la difusión de la cultura de mercado valores. Asimismo resulta revelador que el $46 \%$ no participe en el mercado por preferir no divulgar la información de su empresa.

Resulta explicable porque 769 grandes empresas en el país, equivalente al $84 \%$ de las grandes empresas, no participan del mercado de valores en el Perú, que como consecuencia el reducido número de empresas ascendente a 144, resulta ser el origen del déficit de Instrumentos financieros de deuda y capital.

Se establece ausencia de una regulación efectiva y promotora del mercado de valores en el Perú, con enfoque económico, de mercado y no legalista. La Superintendencia de Mercado de Valores debe fortalecer la regulación y desarrollar acciones de comunicación más amplias para difundir entre pequeños y medianos empresarios, profesionales y población en general acerca de los beneficios y ventajas del mercado de valores.

\section{CONCLUSIONES}

1. El Mercado de Valores constituye una importante alternativa de financiamiento para el sector empresarial peruano, cuya característica se puede apreciar a través de los mecanismos de emisiones de oferta pública primaria de bonos, en que tuvo una evolución ascendente durante los años 2003-2009, alcanzando \$ 7,046 millones valores inscritos en el 2009, superior a los \$ 1,759 en el 2003.

2. El mercado de valores peruano aún es incipiente debido a la poca participación de inversionistas y a la reducida participación de empresas con destacadas calificaciones económicas y financieras para acceder a este mercado, como ocurre que de las 913 grandes empresas solo 144 participan en el mercado equivalente al 16\% comprendida en las 220 empresas al 2010.

3. La legislación vigente del mercado de valores encarece el costo de acceso de empresas a emitir bonos y acciones, por lo que se debe evaluar para su adecuación. Este encarecimiento se debe a los elevados trámites en el proceso de emisiones, cuyo costo es más del 3\% para emisión de 5 millones de dólares para bonos.

4. En la medida que el mercado de valores no supere las restricciones, se elevará el déficit de la oferta de instrumentos financieros conllevando a que mayores capitales acumulados en el Perú, como los de las AFP, se inviertan en el exterior en beneficio de empresas extranjeras.

5. El $37 \%$ de las empresas estarían motivadas a ingresar al mercado de valores con flexibilización de requisitos de las emisiones, el 40\% no participan por la regulación engorrosa, $46 \%$ no participan por los altos costos, el $51 \%$ considera que se debe mejorar la difusión de la cultura de mercado valores y lo revelador ha sido que el 46\% de las grandes empresas no participan en el mercado porque prefiere no divulgar información de su empresa.

6. Se deben desarrollar mecanismos de protección para los accionistas minoritarios impulsando medidas eficaces de transparencia, como decisiones oportunas de parte de la Reguladora (Caso CALLALTI, TUMAN) promoviendo equidad para todos los involucrados en el mercado de valores.

7. Los accionistas minoritarios deben tener la posibilidad de participar en un comité de auditoría para que sus decisiones tengan influencia y repercutan en sus acciones.

8. El buen gobierno corporativo es un elemento esencial en la búsqueda de eficiencia de una Bolsa de Valores, puesto que contempla aspectos de gestión relacionados con la gerencia empresarial, el Directorio, los accionistas y los grupos de interés en torno a la empresa.

9. Las operaciones en el mercado bursátil han venido describiendo una tendencia creciente y 
muy activa de acuerdo al crecimiento del PBI. Esta evolución se aprecia en su rentabilidad generada entre el 2003 y 2009, en el 2003 la rentabilidad de $76.34 \%$ (IGBVL) se eleva al nivel de $117.75 \%$ en el 2009 , luego de una notable caída del -61.52\% (IGBVL) en el 2008, sin embargo cabe señalar que la rentabilidad descendió a -13. 21\% en el 2011 y levemente alcanzo $12 \%$ en el 2012.

10. Ausencia de una regulación efectiva y promotora del mercado de valores en el Perú, por lo que se debe adoptar políticas y medidas con enfoque económico, de mercado y no legalista para fortalecer la regulación y desarrollar acciones de comunicación y promoción acerca de los beneficios y ventajas del mercado de valores.

\section{LITERATURA CITADA}

Deficiencias estructurales de la oferta de activos financieros en el mercado de valores del Perú-2000-2008). Tesis de Doctor, de Pablo Mauricio Pachas.

MONTOSO, C. y NAVARRO, A. (2010). Estimación de la Q de Tobin para la economía peruana. Revista Estudios Económicos BCRP. Lima: BCRP,

BALBAS, A. (2008). Las Matemáticas de la Economía Financiera. Revista Real Academia de Ciencias: Exactas, Físicas y Naturales. Madrid.
MARKOWITZ, (1952). Portfolio Selection. The Journal of Finance. Vol. 7.

TOBIN, J. (1969). A general equilibrium approach to monetary theory.Journal of Money Credit and Banking, Vol. 1, N. ${ }^{\circ} 1$.

BLACK, F. y M. SCHOLES (1973). The pricing of options and corporate liabilities. The Journal of Political Economy, N. ${ }^{\circ} 81$.

ROSS, S. (1976). The Arbitrage Theory of Capital Asset Pricing. Journal of Economic Theory, Vol. 13, N 3 .

MERTON, R. (1973). Theory of Rational Option Pricing. Bell Journal of Economics and Management Science, Vol. 4.

PERÚ TOP PUBLICATIONS SAC (2010). Perú: The top 10,000 companies 2010. Lima: Perú Top Publications SAC.

MASCAREÑAS, J. y CACHÓN, J. (1996). Activos y Mercados Financieros: Las Acciones. Madrid: Ediciones Pirámide S.A.

Ley del Mercado de Valores. Decreto Legislativo $\mathrm{N}^{\circ}$ 861. Fecha 22/10/1996.

Ley General de Sociedades. Ley № 26887. Fecha 09/12/1997. 